\title{
Severe Plastic Deformation and Additive Distribution in Mg-Fe to Improve Hydrogen Storage Properties
}

Flavio José Antiqueira ${ }^{a}$, Daniel Rodrigo Leiva ${ }^{b}$, Tomaz Toshimi Ishikawa ${ }^{b}$, Alberto Moreira Jorge

\author{
Junior ${ }^{b}$, Walter José Botta \\ ${ }^{a}$ Programa de Pós Graduação em Ciência e Engenharia de Materiais (PPGCEM), Universidade \\ Federal de São Carlos, Rod. Washington Luiz, km 235, 13565-905, São Carlos, SP, Brazil \\ ${ }^{b}$ Departamento de Engenharia de Materiais, Universidade Federal de São Carlos, Rod. Washington \\ Luiz, km 235, 13565-905, São Carlos, SP, Brazil
}

Received: April 30, 2017; Revised: September 11, 2017; Accepted: October 02, 2017

\begin{abstract}
Magnesium $(\mathrm{Mg})$ is a light metal with relatively low cost. Its hydride $\left(\mathrm{MgH}_{2}\right)$ is interesting for the safe hydrogen storage in solid state and has a high gravimetric capacity of $7.6 \%$. Practical application of $\mathrm{Mg}$ is still hampered by high reaction temperatures and slow kinetics. In order to improve it and focus on more viable industrial processing conditions, $\mathrm{Mg}$ plates, with or without iron ( $\mathrm{Fe}$ ) addition, in the form of wires and powders, were submitted to severe plastic deformation (SPD) in air, starting with extensive cold rolling (ECR), followed by repetitive rolling (ARB). The samples were characterized by X-ray diffraction (XRD), optical microscopy (OM), scanning (SEM) and transmission electron microscopy (TEM). $\mathrm{H}_{2}$ storage properties were evaluated by differential scanning calorimetry (DSC) and Sievert's volumetric method. Mg processed by ECR+ARB resulted in larger grain refinement and densities of cracks than ECR. In addition, Fe in the form of continuous wires was fragmented and resulted in a better distribution of particles than powders, which agglomerated. Thus, finally, the synergetic effect of microstructural features and $\mathrm{Fe}$ as catalyst and its distribution improved activation, kinetics and hydrogen storage capacity.
\end{abstract}

Keywords: $\mathrm{MgH}_{2}$, severe plastic deformation, hydrogen storage materials.

\section{Introduction}

Adverse effects of pollution around the world may be strongly attributed to the continued use of fossil fuels. Even with the current scientific and technological progress, such fuels continue being a significant emitter of greenhouse gases, which promotes climate changes that harmfully, influences the quality of life and general conditions for survival on Earth ${ }^{1}$.

Hydrogen can play a key role as a vector to generating clean energy. However, for its efficient use in stationary power generation devices or for fuelling automotive vehicles, it is necessary creating technological solutions for the entire production chain. One of the major limitations for using hydrogen in a safe, efficient, and economically viable way lies in the question of its more adequate storage and handling means ${ }^{2}$ than in compressed gas cylinders and liquid tanks available nowadays.

As an alternative for such limitations, hydride-forming materials have been developed and extensively studied and tested by various research groups. $\mathrm{MgH}_{2}$ is one of the most attractive hydrides for application as a solid state hydrogen storage material. However, its slow kinetics, due to the low hydrogen diffusion rate $\mathrm{re}^{3,4}$ and also due to oxides and hydroxides formed on its surface, may bring difficulties to the hydrogen diffusion and even blocking $\mathrm{it}^{5,6}$.

*e-mail: fantiqueira@ppgcem.ufscar.b
Several studies have been conducted to generate alternatives to overcome the limitations mentioned above. Regarding hydrogen diffusion, solutions include: nanostructuring of materials; use of catalysts/additives to improve $\mathrm{H}_{2}$ absorption/ desorption kinetic; production of $\mathrm{Mg}$ binary metallic alloys $\left(\mathrm{Mg}_{2} \mathrm{Ni}, \mathrm{Mg}_{2} \mathrm{Al}\right.$, and $\left.\mathrm{Mg}_{2} \mathrm{Si}\right)$, or chemical destabilization of $\mathrm{MgH}_{2}$ with addition of reactive compounds, such as borohydrides, amides and alanates; and nanoconfining of $\mathrm{MgH}_{2}$ in porous carbon or in polymers?

Among available processing routes for the hydride synthesis, one can mention high energy ball milling (HEBM) and, more recently, severe plastic deformation (SPD) techniques, which are presented in diverse application forms. HEBM has been used successfully to prepare Mg-based nanocomposites ${ }^{8-13}$. However, HEBM is hampered by powder surface contamination and oxidation, processing time, and the need for controlled atmosphere for powder manipulation.

In turn, SPD techniques are presented as alternatives for producing materials with ultrafine or even nanosize grains, under a high hydrostatic pressure and relatively low deformation temperatures without significant crossectional changes of the material ${ }^{14-16}$. SPD processing may produce multiple defects in the crystalline lattice, such as vacancies and dislocations, which have a positive effect on the kinetics of hydrogen diffusion ${ }^{17-21}$. Among the SPD techniques, equal 
channel angular pressing (ECAP) ${ }^{22-25}$, accumulative roll bonding $(\mathrm{ARB})^{26}$ and high-pressure torsion (HPT) ${ }^{27,28}$ are the most intensively studied to process Mg-based materials for hydrogen storage applications.

Samples used in this work were processed by extensive cold rolling (ECR) and $\mathrm{ECR}+\mathrm{ARB}$.

In short, $\mathrm{ARB}$ is a technique that repeatedly rolls stacked metal sheets to a high reduction ratio $(50 \%)$, sectioned into two halves, then piled again and rolled. It can introduce an ultra-high plastic deformation without considerable geometric changes in the material's cross-section, which may be occurring with small number of passes ${ }^{26}$. Some studies have shown that $\mathrm{MgH}_{2}$ powder processed by ARB leads to nanoscale grain refinement and improved $\mathrm{H}_{2}$ absorption/ desorption kinetics ${ }^{29,30}$. In addition, ARB is effective to synthesize nanocomposites by the addition of catalysts such as transition metals ${ }^{31}$ and oxides ${ }^{32}$ in the $\mathrm{MgH}_{2}$ matrix of milled powder. ARB was also investigated as a mean to improve the activation of magnesium and its alloys ${ }^{24,33,34,35,36}$.

Even though ECR does not refine the grain size at the same level, it may lead Mg-alloys to have good $\mathrm{H}_{2}$ storage properties because of the presence of preferential texture in the direction of the (002) basal plane of $\mathrm{Mg}^{24,37,38,39}$. The deformation of metals by ECR occurs under high friction and in a non-homogeneous way through their thickness because of the introduction of large amounts of redundant shear-strain on the material's surface ${ }^{40}$. Ueda et al. ${ }^{38}$ were one of the first to investigate ECR in the synthesis of materials for hydrogen storage when producing Mg-Ni using stacked sheets of $\mathrm{Mg}$ and $\mathrm{Ni}$, followed by heat treatment. Dufour and Huot $^{33}$ investigated the Mg-Pd system, showing that ECR samples have higher resistance to the air contamination than their counterparts prepared by HEBM. Other Mg-based

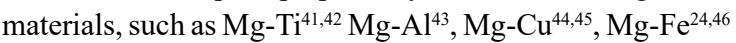
and commercial $\mathrm{Mg}-\mathrm{Zr}-\mathrm{Zn}$ alloys were also investigated ${ }^{34}$.

Based on the limited information available, the objective of the present investigation was to analyze the processing routes of ECR and ECR followed by ARB in commercial coarse-grained magnesium with the addition of $\mathrm{Fe}$ in the form of wires or powders. For comparison, plates of pure $\mathrm{Mg}$ were also processed by ECR and $\mathrm{ECR}+\mathrm{ARB}$. Therefore, the effect of processing routes and the influence of $\mathrm{Fe}$ as an additive in different forms on hydrogen sorption properties were systematically investigated.

\section{Materials and Methods}

The experiments were conducted using commercial coarse-grained magnesium supplied by NORMAG company in the form of an ingot ( $99.8 \%$ purity). Specimens for rolling processes were cut from the ingot in the longitudinal direction and machined to produce small plates of about $1.5 \times 11 \mathrm{x}$ $32 \mathrm{~mm}$. The plates were ground manually to standardize dimensions and flatness. Iron was added in the form of wires or powders. Iron wires $(98.8 \%$ purity) were obtained from commercial steel wool $(0.03 \mathrm{~mm}$ in diameter $)$. The wires were used in the form of continuously unwound wool (LCNT) or as pieces (LFRG) randomly cut from the continuous wool. Both kinds of specimens were compacted in a hydraulic press using $2 \mathrm{Tf}$ and then cut and weighed in the proper ratio with respect to the Mg plates. Fe in the form of powders (PWDR) was supplied by Alfa Aesar (99.998\% purity, \# 22 Mesh). Powders were inserted within a cylindrical tube with $8 \times 32$ $\mathrm{mm}$ (outer diameter $\mathrm{x}$ length) machined out from the $\mathrm{Mg}$ ingot. Both sides of the tubes were closed, and then slightly compacted in a hydraulic press before processing.

$\mathrm{ECR}$ and $\mathrm{ECR}+\mathrm{ARB}$ processing were performed in air under ambient conditions. Sample plates were stacked before processing in the following sequences: (i) $\mathrm{Mg}+\mathrm{Mg}$ (for Pure $\mathrm{Mg}$ ) and (ii) $\mathrm{Mg}+8 \mathrm{~mol} \% \mathrm{Fe}(16.6 \mathrm{wt} \% \mathrm{Fe})+$ $\mathrm{Mg}$. After stacking, the samples were inserted between two $0.8 \mathrm{~mm}$ thick AISI 304 stainless steel plates and then rolled horizontally in a conventional double-reversible rolling mill (FENN/ 55DC02-02A). Six passes were used for ECR and 4 additional passes were applied for ARB. Between each ARB pass, the surfaces of the samples were manually ground with sandpaper and then cleaned with isopropyl alcohol PA (99.5\%). The reduction in each ARB pass was $50 \%$ of the initial thickness. The samples were cut in half length in each pass, stacked, cleaned, and rolled up to a final thickness of $\sim 0.2 \mathrm{~mm}$. After rolling process, the samples were stored in air and left for 30 days in the normal laboratory environment without any special control.

The phases were identified by X-ray diffraction (XRD) using monochromatic $\mathrm{Cu}-\mathrm{K} \alpha$ radiation with $0.154056 \mathrm{~nm}$ wavelength and angular pass of $0.032 \% \mathrm{sec}$ in a Rigaku/ Geigerflex diffractometer equipped with a C-monochromator.

The microstructure was characterized by scanning electron microscopy (SEM) and transmission electron microscopy (TEM). SEM analysis was performed using a FEI/Inspect-S50 and also in a FEG/Philips XL-30, both coupled to an X-ray energy dispersive spectroscopy (EDS) microanalysis system. SEM samples were embedded in bakelite resin, sanded and polished automatically with $1 / 4$ inch diamond paste in a Buehler/MiniMet TM-1000 automatic polishing.

TEM analysis was performed in a FEI /TECNAI G2 F20 HRTEM microscope. TEM samples were ground to a thickness of about $50 \mu \mathrm{m}$, then ion-polished in a GATAN/ Model 691 precision ion polishing system.

The desorption analysis was performed in a Netzsch Simultaneous Thermal Analyzer (STA) 449 Jupiter calorimeter which takes simultaneous differential scanning calorimetric (DSC) and thermogravimetric (TG) measurements and quadrupole mass spectrometer (QMS) Aeolos equipment. Hydrogen desorption temperatures were measured during continuous heating during DSC, using purified and dried argon gas in an overflow regime. The buoyancy effect was considered due to the use of argon as a carrier gas and the 
necessary background treatment was performed as usual. Samples weighting 10-15 mg were placed in $\mathrm{Al}_{2} \mathrm{O}_{3}$ crucibles and heated under a rate of $10^{\circ} \mathrm{C} / \mathrm{min}$ up to $500^{\circ} \mathrm{C}$.

The hydrogenation and kinetic measurements of hydrogen absorption were carried out using a Sieverts apparatus with the samples hydrogenated at $623 \mathrm{~K}\left(350^{\circ} \mathrm{C}\right)$ under a hydrogen pressure of 20 bar for absorption and 0.4 bar vacuum for desorption.

\section{Results and Discussion}

Figures 1a to 1f show XRD patterns taken on the longitudinal plane of $\mathrm{Mg}-8 \mathrm{~mol} \%$ Fe samples, with different morphologies of Fe, after processing by ECR (left hand side) and $\mathrm{ECR}+\mathrm{ARB}$ (right hand side). These patterns reveal the presence of $\alpha-\mathrm{Mg}$ and Fe but, when one compares the theoretical and observed relative intensities, it is apparent that the $\alpha$-Mg phase has preferred orientations in different conditions of Fe morphology and processing routes. Table 1 resumes all the relative intensities for the three main peaks of $\alpha-\mathrm{Mg}$. From Table 1 is possible to observe that phase $\alpha-\mathrm{Mg}$ has changed preferred orientations between ECR and $\mathrm{ECR}+\mathrm{ARB}$ only for LCNT and PWDR Fe morphologies along the pyramidal (101) plane, prismatic (100), which are activated at high temperatures, and basal (002) plane. However, in any condition the orientation become more pronounced in the (002) plane. One can also observe that, except for LFRG morphology, after ECR+ARB textures increased and became higher for the LCNT condition, which grows at the expense of all other orientations. Pure $\mathrm{Mg}$ (Not shown here), had the same behavior as for other samples regarding the (002) orientation. The (002) orientation is the main slip plane of $\alpha$-Mg and, as observed earlier ${ }^{47,48,49,50}$, is one of the best orientation for hydrogen absorption.

Figures $2 \mathrm{a}$ to $2 \mathrm{f}$ show backscattered electrons (BSE) SEM micrographs for samples of $\mathrm{Mg}-8 \mathrm{~mol} \% \mathrm{Fe}$, with different morphologies of Fe (LCNT, LFRG, PWDR), after ECR+ARB processing. From these pictures, one can observe that there was fragmentation of iron wires and that particles are well distributed for samples with LCNT morphology. However, it appears that there was agglomeration of particles of Fe with the LFRG and PWDR morphologies and the distribution of Fe particles are not as good as for the LCNT one, being worst for the PWDR. Obviously, cracks appeared after ECR+ARB processing. Nevertheless, as all the samples were processed in the same way, it is correct supposing that cracks' densities are similar for any condition, but (not shown here) having smaller densities after ECR processing only.

In addition, Figure 2 shows that there is the presence of $\mathrm{Mg}$ oxide around Fe particles, characterized by the dark contrast around them. It is worth remembering that samples were exposed to the air for 30 days and oxide layers are
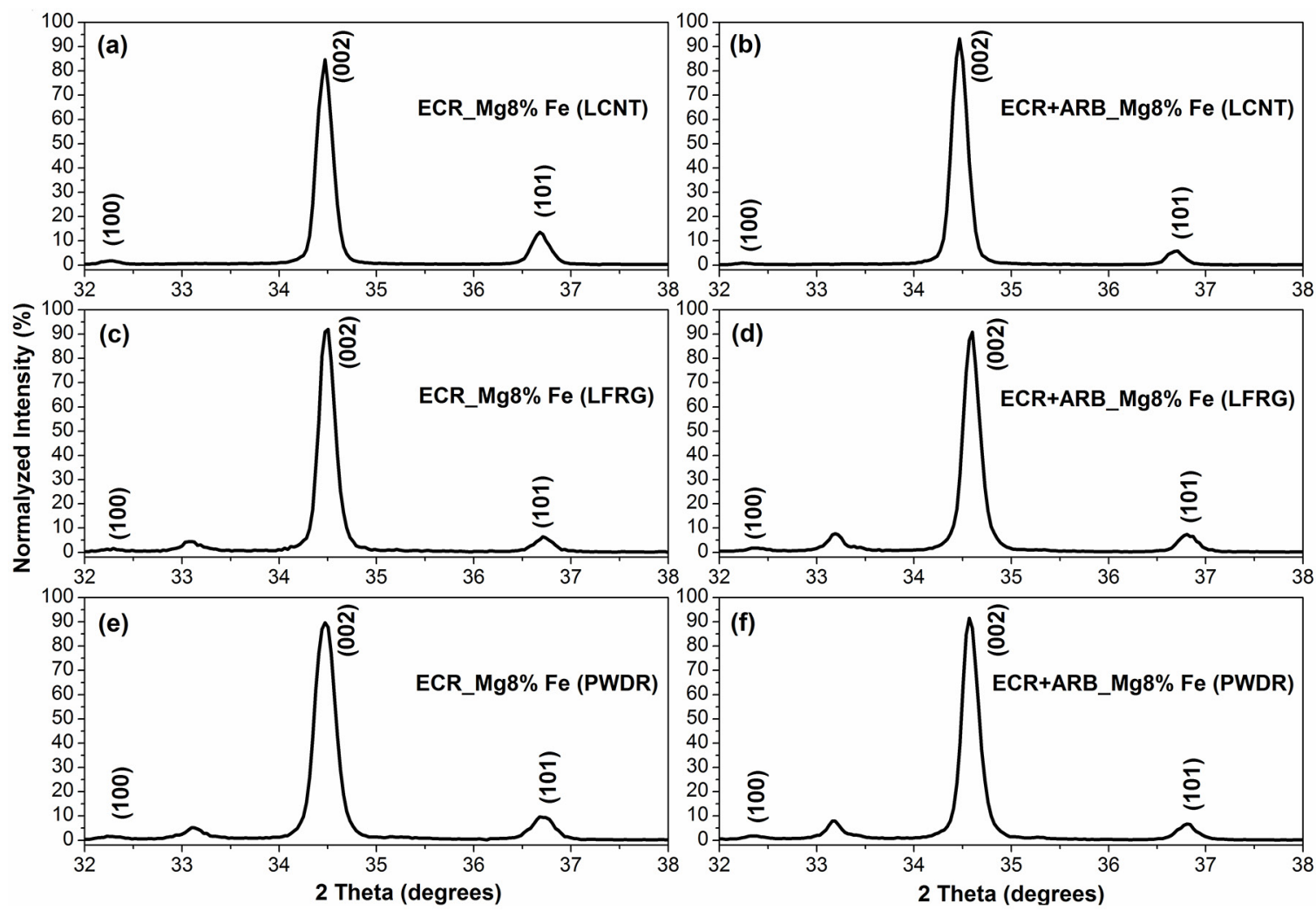

Figure 1. XRD patterns of longitudinal section of Mg- 8 mol\% Fe samples, comparing samples processed by ECR (left hand side) and by ECR+ARB (right hand side) with the folowing morphologies for Fe: $(a, b)$ LCNT, $(c, d)$ LFRG and (e,f) PWDR. 
Table 1. Summary of normalized relative intensities for the three main peaks of $\alpha$-Mg observed in Fig.1.

\begin{tabular}{|c|c|c|c|c|c|c|}
\hline \multirow{3}{*}{ Sample Condition } & \multicolumn{3}{|c|}{ ECR } & \multicolumn{3}{|c|}{$\mathrm{ECR}+\mathrm{ARB}$} \\
\hline & \multicolumn{3}{|c|}{ Relative Intensities (\%) } & \multicolumn{3}{|c|}{ Relative Intensities (\%) } \\
\hline & $\left(\begin{array}{lll}1 & 0 & 0\end{array}\right)$ & $\left(\begin{array}{lll}0 & 0 & 2\end{array}\right)$ & $\left(\begin{array}{lll}1 & 0 & 1\end{array}\right)$ & $\left(\begin{array}{lll}1 & 0 & 0\end{array}\right)$ & $\left(\begin{array}{lll}0 & 0 & 2\end{array}\right)$ & $\left(\begin{array}{lll}1 & 0 & 1\end{array}\right)$ \\
\hline LCNT & 2.7 & 84.5 & 12.8 & 0 & 92.5 & 7.5 \\
\hline LFRG & 2,4 & 90 & 7.6 & 2.5 & 89.7 & 7.8 \\
\hline PWDR & 2.6 & 87.4 & 10 & 2.5 & 90 & 7.5 \\
\hline
\end{tabular}

expected to be formed. However, it is interesting that the concentration of oxides was larger around Fe particles. This behavior is in accordance with another work $^{51}$, where impurities on the surface of $\mathrm{Mg}$ were studied after exposure to ambient conditions. The results evidenced by Secondary Ion Mass Spectrometry (SIMS) imaging showed also localized oxidation occurring around Fe inclusions. This intensified local reactivity in the vicinity of the inclusions was attributed to the galvanic coupling in the presence of adsorbed humidity.

Figures $3 \mathrm{a}$ to $3 \mathrm{~d}$ show TEM micrographs for the sample of Mg-8 mol\% Fe with the LCNT morphology, taken at the longitudinal section of the sample after $\mathrm{ECR}+\mathrm{ARB}$ processing. It is also evident that there are large numbers of dislocations within the grains, evidencing that the sample was not totally recrystallized and subgrains may be still present. In these images one can see clear evidence of a bimodal distribution of grains/subgrains. Measurements gave average grain/subgrain sizes of $\sim 1.0 \mu \mathrm{m}$. Similar results for grain/subgrain sizes were obtained for other Fe morphologies. However, as expected, for samples processed only by ECR (not shown here) grain sizes were found to be $\sim 10 \mu \mathrm{m}$ on average.

Figure 4 shows XRD patterns taken on the longitudinal plane of samples of Mg- $8 \mathrm{~mol} \% \mathrm{Fe}$ with the LCNT morphology processed by ECR and ECR+ARB after 3 cycles of hydrogen absorption and desorption. XRDs were normalized based on the maximum intensity of each spectrum. As one can observe, after absorption samples processed either by ECR or ECR+ARB show the existence of remaining unreacted $\alpha-\mathrm{Mg}$ phase with a high content of preferential texture in the (002) plane. Additionally, the $\mathrm{H}_{2}$ absorption promoted the formation of the $\beta-\mathrm{MgH}_{2}$ hydride with a preferential texture in the (110) plane. In fact, this behavior was anticipated in an investigation of the structural and hydrogen storage properties in nanostructured thin films of $\mathrm{Mg}$ deposited on Si (001) substrates, where Singh et $\mathrm{al}^{52}$ showed by X-ray diffraction that the conversion of $\mathrm{Mg}$ to $\mathrm{MgH}_{2}$ follows a martensitic-like orientation relationship with $\mathrm{Mg}$ (002) // $\mathrm{MgH}_{2}$ (110). In this way, it is expected that a high textured $\mathrm{Mg}$ will produce a high textured hydride, as also observed elsewhere ${ }^{48}$.

After hydrogen desorption, all other peaks of $\beta-\mathrm{MgH}_{2}$ decrease to a minimum, followed by the return of the $\alpha-\mathrm{Mg}$ texture fiber in the (002) plane, showing not only that the reaction of hydride formation is by nucleation and growth, but also the reversibility of the above martensitic-like orientation relationship ${ }^{52}$ and their close relationship during the absorption/desorption ${ }^{47,52}$.

Figures $5 \mathrm{a}$ to $5 \mathrm{~d}$ show BSE-SEM micrographs for the center of the sample of Mg-8 mol\% Fe with the LCNT morphology, taken at the longitudinal section of the sample processed by ECR+ARB after 3 cycles of hydrogen absorption and desorption. From Figs.5 ( $\mathrm{a}$ and b), it is clearly observed the presence of fragmented Fe particles (white contrast), the $\mathrm{Mg}$ matrix with a light gray contrast and $\mathrm{MgH}_{2}$ with a darker contrast. In the interior of sample, $\mathrm{MgH}_{2}$ is concentrated in regions near cracks exposed on the surface and Fe particulate. After desorption, same contrasts are observed in Figs 5 (c and d). However, as observed in Fig. 4, the sample is not completely desorbed. Thus, Figs 5 (c and d) confirms that, even in small quantities, $\mathrm{MgH}_{2}$ is preferentially located close to cracks and Fe particulate. These observations are in accordance with the literature ${ }^{36,41}$ where it is found that, in general, there are a number of preferred sites for the nucleation of $\mathrm{MgH}_{2}$, i.e., in the vicinity of particles incorporated as additives, near cracks, in contact of processing interfaces, other defect sites within the Mg matrix, and, obviously, also on the free outer surface of the compound.

Figure 6 shows the DSC thermograms of $\mathrm{Mg}-8 \mathrm{~mol} \% \mathrm{Fe}$ samples with different morphologies of $\mathrm{Fe}$ and processed by $\mathrm{ECR}$ and ECR + ARB after 3 cycles of hydrogen absorption. All curves are composed by a single endothermic peak. Just for comparison, pure $\mathrm{Mg}$ processed only by ECR presents smaller enthalpy, meaning a smaller amount of desorbed hydrogen, and the highest onset and peak desorption temperatures, being $433^{\circ} \mathrm{C}$ and $445^{\circ} \mathrm{C}$. On the other hand, additional $\mathrm{ARB}$ processing of pure $\mathrm{Mg}$ caused a decrease in the onset and peak desorption temperatures to $418^{\circ} \mathrm{C}$ and $437^{\circ} \mathrm{C}$, respectively, and an increased amount of desorbed hydrogen, which is given by the increased enthalpy of the peak, thus showing the effectiveness of the ARB in improving the desorption kinetics of pure $\mathrm{Mg}$. This effect may be ascribed to the very large difference in grain sizes resulted from one kind of processing to another $(\sim 10 \mu \mathrm{m}$ for ECR and $\sim 1 \mu \mathrm{m}$ for $\mathrm{ECR}+\mathrm{ARB}$ ) and densities of cracks also resulted from the different processing routes, which was smaller in the case of just ECR.

On the other hand, all samples with Fe addition processed by ECR or ECR+ARB presented lower onset and peak desorption temperatures than pure $\mathrm{Mg}$ processed either by ECR 


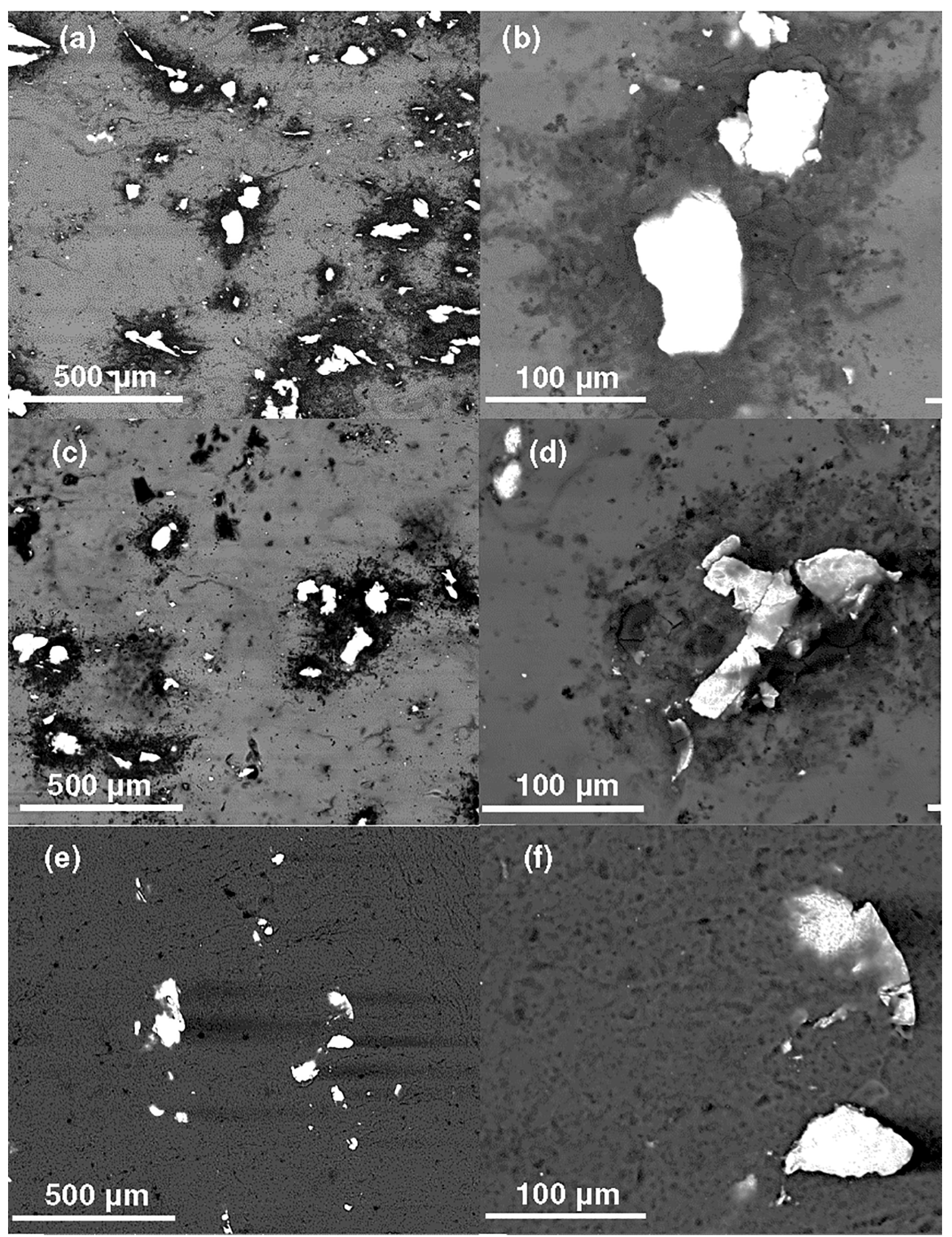

Figure 2. BSE-SEM micrographs ( $25 \mathrm{kV} / 9.8 \mathrm{~mm}$ - work distance $/ 5.0$ - spot $)$ of $\mathrm{Mg}-8 \mathrm{~mol} \% \mathrm{Fe}$ samples after processing by ECR $+\mathrm{ARB}$, with the folowing morphologies for Fe: (a, b, LCNT, (c,d) LFRG and (e,f) PWDR. 


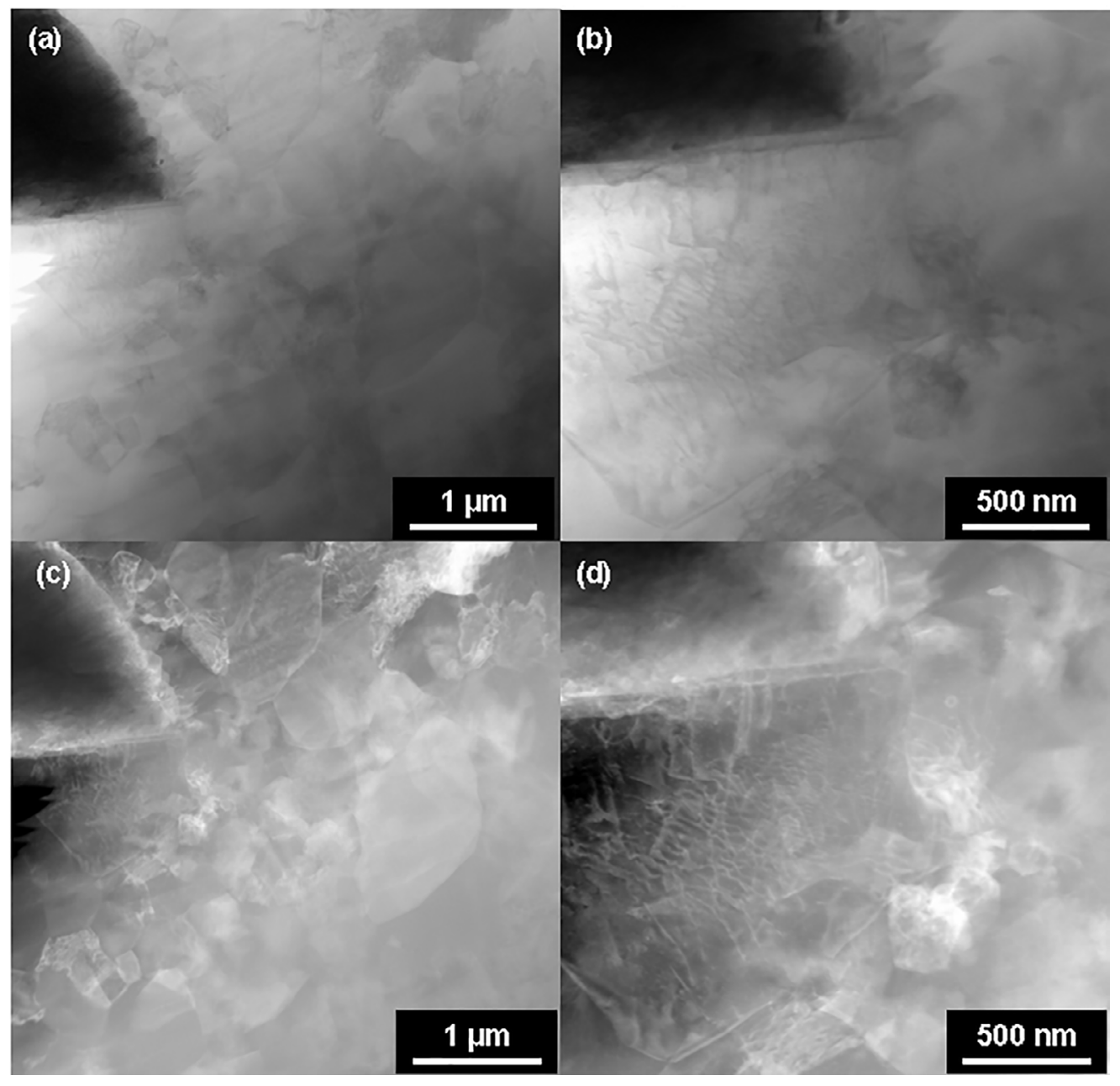

Figure 3. TEM Micrographs ( $200 \mathrm{kV}$ ) for the sample of Mg- $8 \mathrm{~mol} \% \mathrm{Fe}$ with the LCNT morphology, taken at the longitudinal section of the sample after ECR + ARB processing. (a, b) Bright Field (BF) images and (c, d) Dark Field (DF) images.

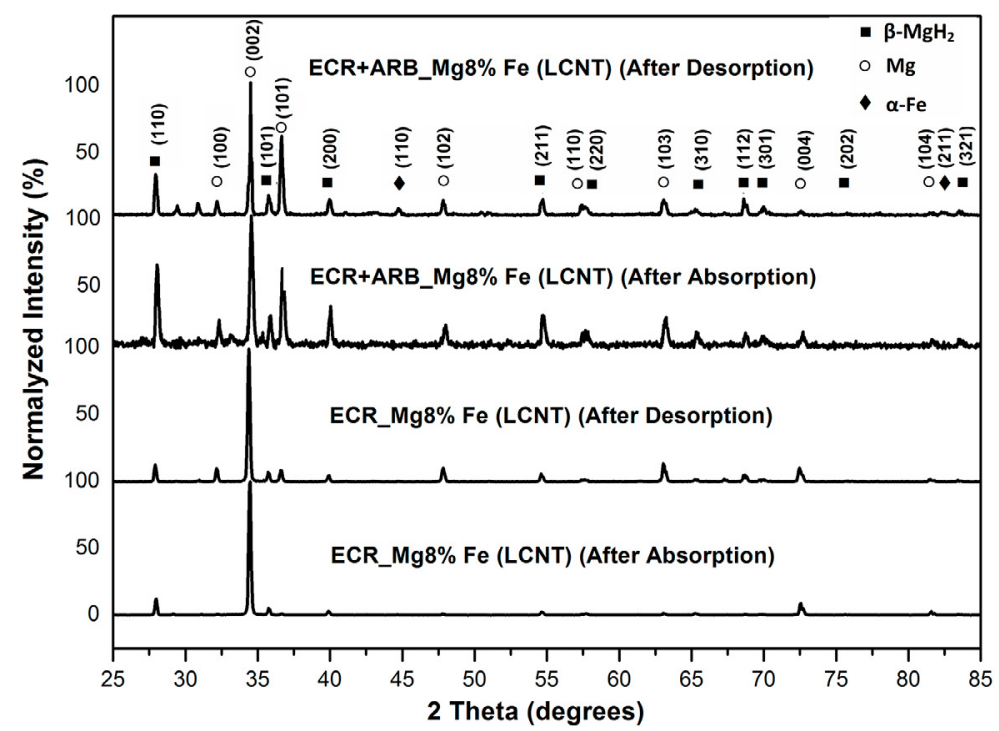

Figure 4. XRD patterns of longitudinal section of Mg- 8 mol\% Fe samples with LCNT morpholofy after the third cycle of $\mathrm{H}_{2}$ absorption and desorption, comparing samples processed by ECR and ECR + ARB. 


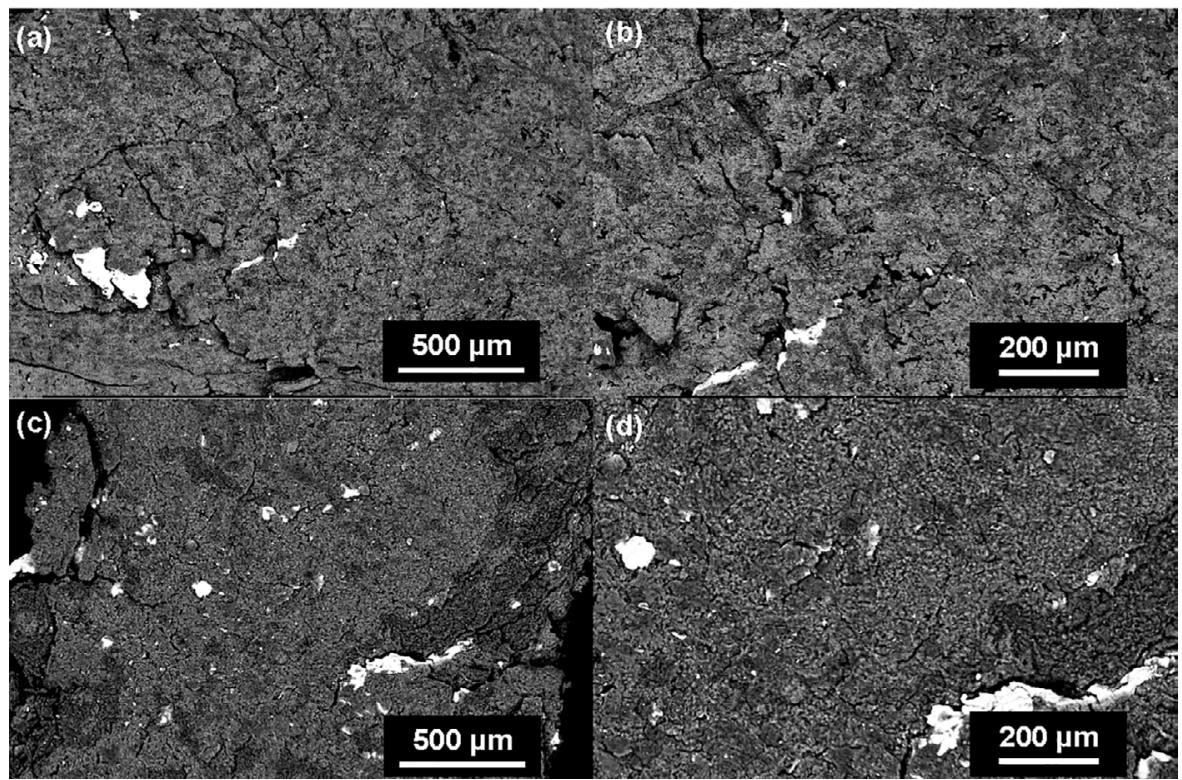

Figure 5. BSE-SEM micrographs ( $25 \mathrm{kV} / 10.1 \mathrm{~mm}$ - work distance $/ 3.0$ - spot) for samples of $\mathrm{Mg}-8 \mathrm{~mol} \%$ $\mathrm{Fe}$, with the LCNT morphology processed by ECR + ARB after 3 cycles of hydrogen absorption and desorption: ( $a, b)$ after absorption; (c, d) after desorption

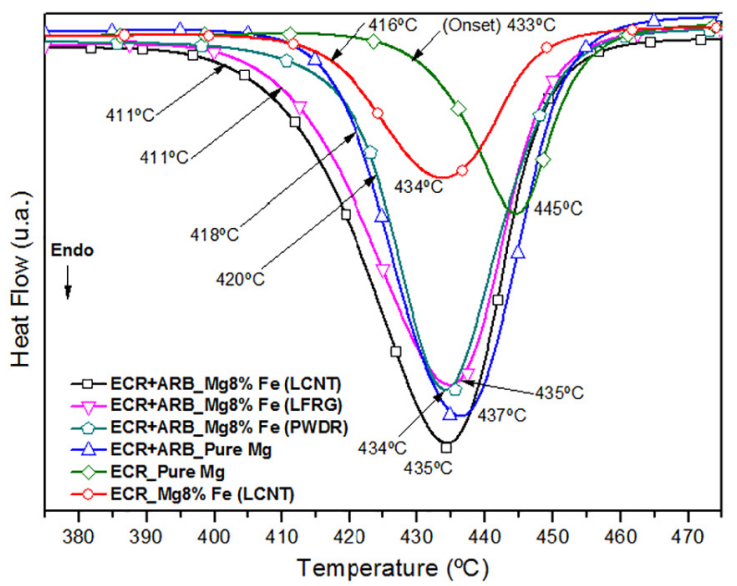

Figure 6. DSC thermograms of $\mathrm{Mg}-8 \mathrm{~mol} \% \mathrm{Fe}$ samples with different morphologies of Fe processed by ECR and ECR+ARB after 3 cycles of hydrogen absorption.

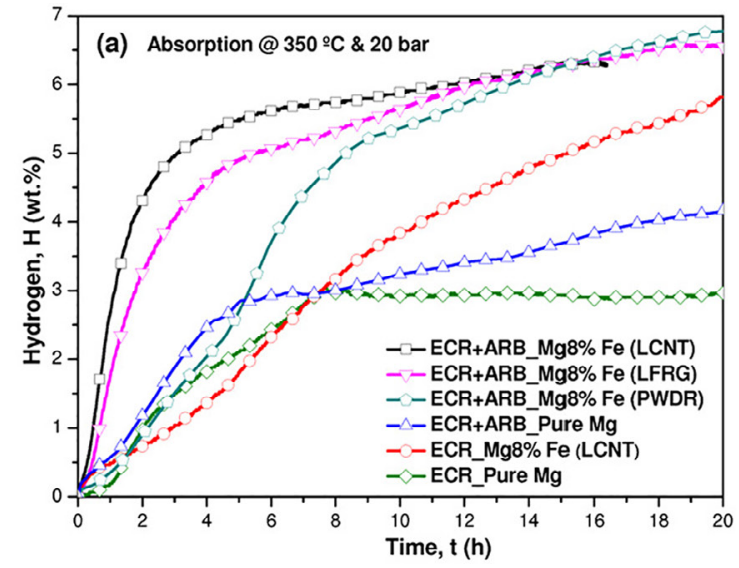

or $\mathrm{ECR}+\mathrm{ARB}$, showing that Fe played a role acting as a catalyst. However, it is also possible to emphasize that the distribution of Fe also influenced. In other words, onset and peak temperatures are directly related to the observed distribution of Fe (Fig. 2), which was in the sequence of LCNT, LFRG and PWDR. The same trend was observed for enthalpies, whose intensities changed according the above sequence. Furthermore, grain sizes and density of cracks also influenced in the desorption behavior, following the same trend as for pure $\mathrm{Mg}$.

Figure 7 show the kinetic curves belonging to the first cycle (activation) at $350^{\circ} \mathrm{C}$ and $20 \mathrm{bar}_{2}$ at absorption and $350{ }^{\circ} \mathrm{C}$ and vacuum at the desorption, for pure $\mathrm{Mg}$ and $\mathrm{Mg}-8$ mol\% Fe (LCNT, LFRG and PWDR) processed by ECR and $\mathrm{ECR}+\mathrm{ARB}$. From these curves, it was possible to observe that absorption or desorption were influenced by the same factor as observed in the DSC curves presented in Fig. 6,

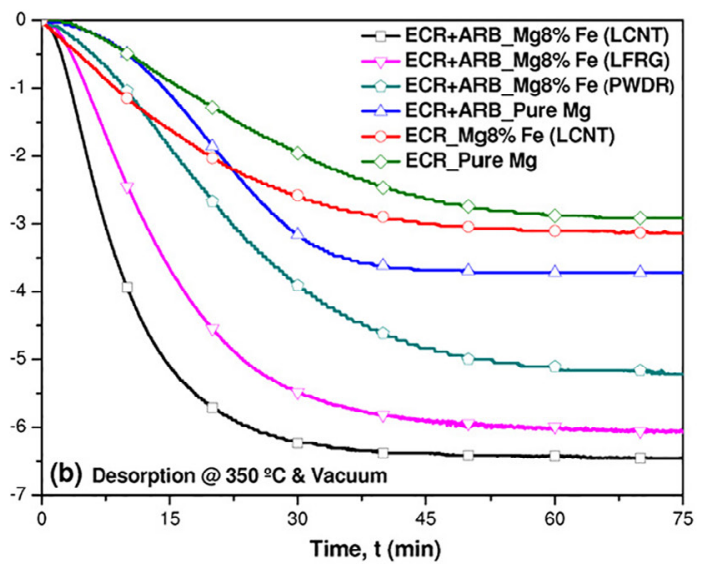

Figure 7. Knetic curves of pure Mg and Mg- 8 mol\% Fe (LCNT, LFRG and PWDR) processed by ECR and ECR+ARB, (a) for absorption@350 ${ }^{\circ} \mathrm{C} / 20$ bar $\mathrm{H}_{2}$ and (b) desorption @ $350^{\circ} \mathrm{C}$ under vacuum. 
i.e., the positive effect of iron and its distribution, the large difference in grain sizes resulted from one kind of processing to another and also densities of cracks also resulted from the different processing routes. In this sense, ECR+ARB processing produced different distribution of iron (Fig. 2). The best one led to a faster kinetics and larger capacities of absorption and desorption, which varied in the same sequence observed in Fig. 2, for LCNT, LFRG and PWDR, respectively. In addition, ARB decreased grain sizes and increased the amounts of cracks, which also assisted kinetics, improved capacities and even avoided incubation times.

In the case of this work, textures were very similar for both processing routes ECR and ECR+ARB. Therefore, its influence is impossible to be discernible for any processing condition.

\section{Summary}

$\mathrm{ECR}+\mathrm{ARB}$ processing produced relative intensities for the (002) texture, similar to as for samples processed only by ECR. Thus, its influence in the hydrogen sorption properties was not apparent in the results. In turn, iron played a role in the acquired hydrogen sorption properties by improving kinetics and the reversible capacity over unprocessed magnesium. $\mathrm{ARB}+\mathrm{ECR}$ processing fragmented Fe wires in the LCNT morphology and promoted redistribution of $\mathrm{Fe}$ particles in all Fe morphologies, leading to agglomeration of particles in the LFRG and the PWDR morphologies. ARB+ECR processing led to a very high grain refinement, producing grain sizes of $\sim 1 \mu \mathrm{m}$, while ECR processing produced grain sizes of $\sim 10$ $\mu \mathrm{m}$. In addition, a higher density of cracks appeared after $\mathrm{ARB}+\mathrm{ECR}$, when compared to ECR. Thus, the above set of features led to the best hydrogen sorption properties for $\mathrm{ECR}+\mathrm{ARB}$ processing due to grain size reduction, increased density of cracks and promoting redistribution of $\mathrm{Fe}$, which in turn improved sorption properties in the following sequence of iron morphologies: LCNT, LFRG and PWDR.

\section{Acknowledgements}

We would like to thank the Brazilian agencies FAPESP, CAPES and CNPq for their support.

\section{References}

1. Jörissen L. Prospects of hydrogen as a Future Energy Carrier. In: McPhail SJ, Cigolotti V, Moreno A. Fuel Cells in the Wasteto-Energy Chain. London: Springer; 2012. p. 189-203.

2. Varin RA, Czujko T, Wronski ZS. Nanomaterials for Solid State Hydrogen Storage. New York: Springer. 2009. 346 p.

3. Töpler J, Buchner H, Säufferer H, Knorr K, Prandl W. Measurements of the diffusion of hydrogen atoms in magnesium and $\mathrm{Mg}_{2} \mathrm{Ni}$ by neutron scattering. Journal of the Less Common Metals. 1982;88(2):397-404.
4. Huot J, Liang G, Boily S, Van Neste A, Schulz R. Structural study and hydrogen sorption kinetics of ball-milled magnesium hydride. Journal of Alloys and Compounds. 1999;293-295:495500.

5. Manchester FD, Khatamian D. Mechanisms for Activation of Intermetallic Hydrogen Absorbers. Materials Science Forum. 1988;31:261-296.

6. Zaluska A, Zaluski L, Ström-Olsen JO. Nanocrystalline magnesium for hydrogen storage. Journal of Alloys and Compounds. 1999;288(1-2):217-225.

7. Jia Y, Sun C, Shen S, Zou J, Mao SS, Yao X. Combination of nanosizing and interfacial effect: Future perspective for designing Mg-based nanomaterials for hydrogen storage. Renewable and Sustainable Energy Reviews. 2015;44:289-303.

8. Sakintuna B, Lamari-Darkrim F, Hirscher M. Metal hydride materials for solid hydrogen storage: A review. International Journal of Hydrogen Energy. 2007;32(9):1121-1140.

9. Yavari AR, LeMoulec A, de Castro FR, Deledda S, Friedrichs $\mathrm{O}$, Botta WJ, et al. Improvement in $\mathrm{H}$-sorption kinetics of $\mathrm{MgH}_{2}$ powders by using $\mathrm{Fe}$ nanoparticles generated by reactive $\mathrm{FeF}_{3}$ addition. Scripta Materialia. 2005;52(8):719-724.

10. de Castro JFR, Yavari AR, LeMoulec A, Ishikawa TT, Botta Filho WJ. Improving $\mathrm{H}$-sorption in $\mathrm{MgH}_{2}$ powders by addition of nanoparticles of transition metal fluoride catalysts and mechanical alloying. Journal of Alloys and Compounds. 2005;389(1-2):270-274.

11. Deledda S, Borissova A, Poinsignon C, Botta WJ, Dornheim $\mathrm{M}, \mathrm{Klassen} \mathrm{T}$. H-sorption in $\mathrm{MgH}_{2}$ nanocomposites containing $\mathrm{Fe}$ or $\mathrm{Ni}$ with fluorine. Journal of Alloys and Compounds. 2005;404-406:409-412.

12. de Rango P, Chaise A, Charbonnier J, Fruchart D, Jehan M, Marty $\mathrm{P}$, et al. Nanostructured magnesium hydride for pilot tank development. Journal of Alloys and Compounds. 2007;446447:52-57.

13. Vaichere A, Leiva DR, Ishikawa TT, Botta WJ. Synthesis of $\mathrm{MgH}_{2}$ and $\mathrm{Mg}_{2} \mathrm{FeH}_{6}$ by Reactive Milling of Mg-based Mixtures Containing Fluorine and Iron. Materials Science Forum. 2008;570:39-44

14. Valiev RZ, Islamgaliev RK, Alexandrov IV. Bulk nanostructured materials from severe plastic deformation. Progress in Materials Science. 2000;45(2):103-189.

15. Valiev RZ, Langdon TG. Principles of equal-channel angular pressing as a processing tool for grain refinement. Progress in Materials Science. 2006;51(7):881-981.

16. Zhilyaev AP, Langdon TG. Using high-pressure torsion for metal processing: Fundamentals and applications. Progress in Materials Science. 2008;53(6):893-979.

17. Fukai Y. Formation of superabundant vacancies in metal hydrides at high temperatures. Journal of Alloys and Compounds. 1995;231(1-2):35-40

18. Fukai Y. Formation of superabundant vacancies in M-H alloys and some of its consequences: A review. Journal of Alloys and Compounds. 2003;356-357:263-269. 
19. Schafler E, Steiner G, Korznikova E, Kerber M, Zehetbauer MJ. Lattice defect investigation of ECAP-Cu by means of X-ray line profile analysis, calorimetry and electrical resistometry. Materials Science and Engineering: A. 2005;410-411:169-173.

20. Wieczorek AK, Krystian M, Zehetbauer MJ. SPD Processed Alloys as Efficient Vacancy-Hydrogen Systems. Solid State Phenomena. 2006;114:177-182.

21. Sauvage X, Wetscher F, Pareige P. Mechanical alloying of $\mathrm{Cu}$ and $\mathrm{Fe}$ induced by severe plastic deformation of a $\mathrm{Cu}-\mathrm{Fe}$ composite. Acta Materialia. 2005;53(7):2127-2135.

22. Skripnyuk VM, Rabkin E, Estrin Y, Lapovok R. The effect of ball milling and equal channel angular pressing on the hydrogen absorption/desorption properties of Mg- $4.95 \mathrm{wt} \% \mathrm{Zn}-0.71 \mathrm{wt} \%$ Zr (ZK60) alloy. Acta Materialia. 2004;52(2):405-414.

23. Skripnyuk VM, Rabkin E, Estrin Y, Lapovok R. Improving hydrogen storage properties of magnesium based alloys by equal channel angular pressing. International Journal of Hydrogen Energy. 2009;34(15):6320-6324.

24. Leiva DR, Fruchart D, Bacia M, Girard G, Skryabina N, Villela ACS, et al. Mg alloy for hydrogen storage processed by SPD. International Journal of Materials Research. 2009;100(12):1739-1746.

25. Krystian M, Zehetbauer MJ, Kropik H, Mingler B, Krexner G. Hydrogen storage properties of bulk nanostructured ZK60 Mg alloy processed by Equal Channel Angular Pressing. Journal of Alloys and Compounds. 2011;509(Suppl. 1):S449-S455.

26. Saito Y, Utsunomiya H, Tsuji N, Sakai T. Novel ultra-high straining process for bulk materials-development of the accumulative roll-bonding (ARB) process. Acta Materialia. 1999;47(2):579-583.

27. Botta WJ, Jorge AM Jr., Veron M, Rauch EF, Ferrie E, Yavari $\mathrm{AR}$, et al. H-sorption properties and structural evolution of $\mathrm{Mg}$ processed by severe plastic deformation. Journal of Alloys and Compounds. 2013;580(Suppl 1):S187-S191.

28. Leiva DR, Huot J, Ishikawa TT, Bolfarini C, Kiminami CS, Jorge AM Jr., et al. Hydrogen Activation Behavior of Commercial Magnesium Processed by Different Severe Plastic Deformation Routes. Materials Science Forum. 2010;667-669:1047-1051.

29. Leiva DR, Floriano R, Huot J, Jorge AM, Bolfarini C, Kiminami $\mathrm{CS}$, et al. Nanostructured $\mathrm{MgH}_{2}$ prepared by cold rolling and cold forging. Journal of Alloys and Compounds. 2011;509(Suppl. 1):S444-S448.

30. Lang J, Huot J. A new approach to the processing of metal hydrides. Journal of Alloys and Compounds. 2011;509(3):L18-L22.

31. Vincent SD, Lang J, Huot J. Addition of catalysts to magnesium hydride by means of cold rolling. Journal of Alloys and Compounds. 2012;512(1):290-295.

32. Bellemare J, Huot J. Hydrogen storage properties of cold rolled magnesium hydrides with oxides catalysts. Journal of Alloys and Compounds. 2012;512(1):33-38.

33. Dufour J, Huot J. Rapid activation, enhanced hydrogen sorption kinetics and air resistance in laminated Mg-Pd 2.5 at.\%. Journal of Alloys and Compounds. 2007;439(1-2):L5-L7.

34. Wang JY, Wu CY, Nieh JK, Lin HC, Lin KM, Bor HY. Improving the hydrogen absorption properties of commercial
$\mathrm{Mg}-\mathrm{Zn}-\mathrm{Zr}$ alloy. International Journal of Hydrogen Energy. 2010;35(3):1250-1256.

35. Amira S, Huot J. Effect of cold rolling on hydrogen sorption properties of die-cast and as-cast magnesium alloys. Journal of Alloys and Compounds. 2012;520:287-294.

36. Jain P, Lang J, Skryabina NY, Fruchart D, Santos SF, Binder K, et al. $\mathrm{MgH}_{2}$ as dopant for improved activation of commercial Mg ingot. Journal of Alloys and Compounds. 2013;575:364369.

37. Huot J, Skryabina NY, Fruchart D. Application of Severe Plastic Deformation Techniques to Magnesium for Enhanced Hydrogen Sorption Properties. Metals (Basel). 2012;2(3):329-343.

38. Ueda TT, Tsukahara M, Kamiya Y, Kikuchi S. Preparation and hydrogen storage properties of $\mathrm{Mg}-\mathrm{Ni}-\mathrm{Mg}_{2} \mathrm{Ni}$ laminate composites. Journal of Alloys and Compounds. 2005;386(1-2):253-257.

39. Takeichi N, Tanaka K, Tanaka H, Ueda TT, Kamiya Y, Tsukahara $\mathrm{M}$, et al. Hydrogen storage properties of $\mathrm{Mg} / \mathrm{Cu}$ and $\mathrm{Mg} / \mathrm{Pd}$ laminate composites and metallographic structure. Journal of Alloys and Compounds. 2007;446-447:543-548.

40. Lee SH, Saito Y, Tsuji N, Utsunomiya H, Sakai T. Role of shear strain in ultragrain refinement by accumulative roll-bonding (ARB) process. Scripta Materialia. 2002;46(4):281-285.

41. Danaie M, Mauer C, Mitlin D, Huot J. Hydrogen storage in bulk $\mathrm{Mg}$-Ti and Mg-stainless steel multilayer composites synthesized via accumulative roll-bonding (ARB). International Journal of Hydrogen Energy. 2011;36(4):3022-3036.

42. Mori R, Miyamura H, Kikuchi S, Tanaka K, Takeichi N, Tanaka $\mathrm{H}$, et al. Hydrogenation Characteristics of Mg Based Alloy Prepared by Super Lamination Technique. Materials Science Forum. 2007;561-565:1609-1612.

43. Suganuma K, Miyamur H, Kikuchi S, Takeichi N, Tanaka K, Tanaka H, et al. Hydrogen Storage Properties of Mg-Al Alloy Prepared by Super Lamination Technique. Advanced Materials Research. 2007;26-28:857-860.

44. Takeichi N, Tanaka K, Tanaka H, Ueda TT, Kamiya Y, Tsukahara $\mathrm{M}$, et al. Hydrogen storage properties of $\mathrm{Mg} / \mathrm{Cu}$ and $\mathrm{Mg} / \mathrm{Pd}$ laminate composites and metallographic structure. Journal of Alloys and Compounds. 2007;446-447:543-548.

45. Tanaka K, Takeichi N, Tanaka H, Kuriyama N, Ueda TT, Tsukahara $\mathrm{M}$, et al. Investigation of micro-structural transition through disproportionation and recombination during hydrogenation and dehydrogenation in $\mathrm{Mg} / \mathrm{Cu}$ super-laminates. Journal of Materials Science. 2008;43(11):3812-3816.

46. Leiva DR, Jorge AM, Ishikawa TT, Huot J, Fruchart D, Miraglia S, et al. Nanoscale Grain Refinement and H-Sorption Properties of $\mathrm{MgH}_{2}$ Processed by High-Pressure Torsion and Other Mechanical Routes. Advanced Engineering Materials. 2010;12(8):786-792.

47. Jorge AM Jr., de Lima GF, Triques MRM, Botta WJ, Kiminami CS, Nogueira RP, et al. Correlation between hydrogen storage properties and textures induced in magnesium through ECAP and cold rolling. International Journal of Hydrogen Energy. 2014;39(8):3810-3821. 
48. Jorge AM Jr., Prokofiev E, de Lima GF, Rauch E, Veron $\mathrm{M}$, Botta WJ, et al. An investigation of hydrogen storage in a magnesium-based alloy processed by equal-channel angular pressing. International Journal of Hydrogen Energy. 2013;38(20):8306-8312.

49. Lang J, Skryabina N, Fruchart D, Danaie M, Huot J. Microstructure of Cold Rolled Magnesium and Magnesium Hydrides for Hydrogen Storage Applications. Chemie for Stable Development. 2013;21:599-606.
50. Ungár T. Microstructural parameters from X-ray diffraction peak broadening. Scripta Materialia. 2004;51(8):777-781.

51. McIntyre NS, Chen C. Role of impurities on Mg surfaces under ambient exposure conditions. Corrosion Science. 1998;40(10):1697-1709.

52. Singh S, Eijt SWH, Zandbergen MW, Legerstee WJ, Svetchnikov VL. Nanoscale structure and the hydrogenation of Pd-capped magnesium thin films prepared by plasma sputter and pulsed laser deposition. Journal of Alloys and Coumpouds. 2007;441(12):344-351. 